University of South Florida

DIGITAL COMMONS

Digital Commons @ University of

@ UNIVERSITY OF SOUTH FLORIDA

South Florida

Internal Medicine Faculty Publications

Internal Medicine

$1-1-2011$

\title{
Obesity-Mediated Inflammatory Microenvironment Stimulates Osteoclastogenesis and Bone Loss in Mice
}

\author{
Ganesh V. Halade \\ University of Texas Health Science Center at San Antonio, ghalade@usf.edu \\ Amina El Jamali \\ University of Texas Health Science Center at San Antonio \\ Paul J. Williams \\ University of Texas Health Science Center at San Antonio \\ Roberto J. Fajardo \\ University of Texas Health Science Center at San Antonio \\ Gabriel Fernandes \\ University of Texas Health Science Center at San Antonio
}

Follow this and additional works at: https://digitalcommons.usf.edu/intmed_facpub

\section{Scholar Commons Citation \\ Halade, Ganesh V.; El Jamali, Amina; Williams, Paul J.; Fajardo, Roberto J.; and Fernandes, Gabriel, "Obesity-Mediated Inflammatory Microenvironment Stimulates Osteoclastogenesis and Bone Loss in Mice" (2011). Internal Medicine Faculty Publications. 73. \\ https://digitalcommons.usf.edu/intmed_facpub/73}

This Article is brought to you for free and open access by the Internal Medicine at Digital Commons @ University of South Florida. It has been accepted for inclusion in Internal Medicine Faculty Publications by an authorized administrator of Digital Commons @ University of South Florida. For more information, please contact digitalcommons@usf.edu. 


\title{
Obesity-mediated inflammatory microenvironment stimulates osteoclastogenesis and bone loss in mice
}

\author{
Ganesh V Halade ${ }^{a}{ }^{*}$, Amina El Jamali $^{\mathrm{b}}$, Paul J Williams ${ }^{\mathrm{a}}$, Roberto J Fajardo ${ }^{\mathrm{c}}$, and Gabriel \\ Fernandes ${ }^{a}$ \\ aDivision of Clinical Immunology and Rheumatology, Department of Medicine, University of Texas \\ Health Science Center at San Antonio, 7703 Floyd Curl Drive, Texas 78229-3900, USA. \\ ${ }^{b}$ Division of Nephrology, Department of Medicine, University of Texas Health Science Center at \\ San Antonio, 7703 Floyd Curl Drive, Texas 78229-3900, USA. \\ 'Department of Orthopedics, University of Texas Health Science Center at San Antonio, 7703 \\ Floyd Curl Drive, Texas 78229-3900, USA.
}

\begin{abstract}
Clinical evidence indicates that fat is inversely proportional to bone mass in elderly obese women. However, it remains unclear whether obesity accelerates bone loss. In this report we present evidence that increased visceral fat leads to inflammation and subsequent bone loss in 12-monthold C57BL/6J mice that were fed 10\% corn oil (CO)-based diet and a control lab chow (LC) for 6 months. As expected from our previous work, CO-fed mice demonstrated increased visceral fat and enhanced total body fat mass compared to LC. The adipocyte-specific PPAR $\gamma$ and bone marrow (BM) adiposity were increased in CO-fed mice. In correlation with those modifications, inflammatory cytokines (IL-1 $\beta$, IL-6, TNF- $\alpha$ ) were significantly elevated in COfed mice compared to LC-fed mice. This inflammatory BM microenvironment resulted in increased superoxide production in osteoclasts and undifferentiated BM cells. In CO-fed mice, the increased number of osteoclasts per trabecular bone length and the increased osteoclastogenesis assessed exvivo suggest that $\mathrm{CO}$ diet induces bone resorption. Additionally, the up-regulation of osteoclastspecific cathepsin $\mathrm{k}$ and RANKL expression and down-regulation of osteoblast-specific RUNX2/ Cbfa1 supports this bone resorption in CO-fed mice. Also, COfed mice exhibited lower trabecular bone volume in the distal femoral metaphysis and had reduced OPG expression. Collectively, our results suggest that increased bone resorption in mice fed a CO-enriched diet is possibly due to increased inflammation mediated by the accumulation of adipocytes in the BM microenvironment. This inflammation may consequently increase osteoclastogenesis, while reducing osteoblast development in CO-fed mice.
\end{abstract}

\section{Keywords}

Aging; adipocytes; bone marrow adiposity; obesity; osteoporosis; visceral fat

(C) 2010 Elsevier Inc. All rights reserved.

*Name and address of the corresponding Author: Dr. Ganesh V. Halade, PhD Division of Clinical Immunology and Rheumatology, Department of Medicine, University of Texas Health Science Center at San Antonio, 7703 Floyd Curl Drive, Texas 78229-3900, United Sates of America Phone: 001-210-567-4663 Fax: 001-210-567-4592 halade@uthscsa.edu.

Publisher's Disclaimer: This is a PDF file of an unedited manuscript that has been accepted for publication. As a service to our customers we are providing this early version of the manuscript. The manuscript will undergo copyediting, typesetting, and review of the resulting proof before it is published in its final citable form. Please note that during the production process errors may be discovered which could affect the content, and all legal disclaimers that apply to the journal pertain. 


\section{Introduction}

Obesity has become a critical medical problem (Kopelman, 2000). It is a major cause of mortality and morbidity (Ogden et al., 2006; Powell, 2007). Obesity is reported to be both protective (Kirchengast et al., 2002) and deleterious to bone health status (Villareal et al., 2005). On one hand, it has been proposed that the biomechanical pressure due to an overweight status stimulates bone formation by decreasing apoptosis (Ehrlich and Lanyon, 2002), possibly through the Wnt/ $\beta$-catenin signaling pathway (Bonewald and Johnson, 2008). On the other hand, there are numerous reports that obesity is a risk factor for osteoporosis in humans (Nunez et al., 2007; Rosen and Bouxsein, 2006; Villareal et al., 2005; Zhao et al., 2008) . It has been proposed that lipotoxicity and subsequent inflammation might be responsible for bone loss (Duque, 2008) Several molecular and cellular mechanisms, by which inflammatory events associated with the aging process decrease the bone mass, have been elucidated (Duque, 2008; Mundy, 2007). It has been suggested that increasing amounts of fat in the BM microenvironment (Naveiras et al., 2009) may affect bone turnover, through both the inhibition of osteoblast function and increased osteoclast differentiation/activation (Oh et al., 2010). Murine and human studies have shown that adipose tissue produce pro-inflammatory cytokines, such as Interleukin (IL)- $1 \beta$, IL-6 and Tumor Necrosis Factor (TNF)- $\alpha$. These cytokines are known to stimulate the proliferation and differentiation of osteoclasts (Horowitz et al., 2001; Wu et al., 2007). Interestingly, osteoclastogenesis is closely related to both osteoblastogenesis and adipogenesis. In addition, osteoblasts produce receptor activator of nuclear factor- $\kappa \beta$ ligand (RANKL) and osteoprotegerin (OPG), two critical factors in osteoclast differentiation (Boyle et al., 2003).

Superoxide production, by the osteoclast at the bone interface, is involved in bone matrix degradation (Key et al., 1994). Moreover, bone resorption is characterized by elevated reactive oxygen species (ROS), which adversely affects bone remodeling (Wauquier et al., 2009). While it is proposed that ROS/inflammation and lipotoxicity participates in bone loss, the exact mechanism of obesity-mediated bone loss remained unclear.

The aim of the present study was to investigate whether the bone marrow microenvironment in a murine obesity model is associated with bone resorption. We have selected a corn oil (CO)-enriched diet for this present study, which is widely used in western diets, and is responsible for many diseases (Simopoulos, 2006). We fed a westernized diet containing 10\% CO to 12-month-old C57BL/6J female mice for 6 months. $\mathrm{CO}$ is known to promote age-associated obesity and thus represents a useful model for studying obesity and osteoporosis (Halade et al., 2010). Our work demonstrates that increased bone marrow adiposity influences the microenvironment and results in increased inflammatory cytokine production and osteoclasts formation/differentiation. These processes correlate with enhanced superoxide production in differentiated osteoclasts and undifferentiated BM cells of CO-fed animals. These data collectively suggest that CO-induced obesity leads to bone resorption in a redox-dependent manner. Therefore, the down-regulation of bone adiposity, inflammation and osteoclastogenesis should be beneficial to maintain the bone homeostasis in obesity.

\section{Materials and methods}

\subsection{Reagents and ELISA kits}

$\alpha$-modified minimal essential medium ( $\alpha$-MEM), Roswell Park Memorial Institute (RPMI) 1640 medium, phenol red-free $\alpha$-MEM, Hanks balanced salt solution (HBSS) and fetal bovine serum were purchased from Sigma-Aldrich (St. Louis, MO, USA). Recombinant mouse RANKL and M-CSF were obtained from PeproTech Inc. (Rocky Hill, NJ) and R\&D 
Systems (Minneapolis, MN, USA), respectively. Phorbol 12-myristate 13-acetate (PMA), and superoxide dismutase (SOD) were obtained from Sigma Chemical Co. (St. Louis, MO, USA). The enhancer-containing luminol-based detection system (Diogenes) was obtained from National Diagnostics (Atlanta, GA, USA).

\subsection{Animals and diet}

Eleven-month-old female mice, weighing 25-27 g, were purchased from Jackson Laboratories (Bar Harbor, Maine 04609 USA) and provided water and standard chow American Institute of Nutrition (AIN) 93G (diet recommended by AIN for growth) ad libitum for one month. At 12 months, age-matched and weight-matched animals were randomized into two groups, each containing 15 mice. Subsequently, the animals were housed in a standard controlled animal care facility in cages ( 5 mice/cage) and fed a diet containing $\mathrm{CO}$ and one group maintained on standard lab chow (LC) rodent diet ad libitum for 6 months. The animals were maintained in a temperature-controlled room $\left(22-25^{\circ} \mathrm{C}\right.$, $45 \%$ humidity) on a 12:12-h dark-light cycle. National Institutes of Health guidelines were strictly followed, and all the studies were approved by the Institutional Laboratory Animal Care and Use Committee of the University of Texas Health Science Center (San Antonio, $\mathrm{TX}$ ). Body weight was measured weekly. The CO diet was prepared using $10 \% \mathrm{CO}$ with AIN93 semi-purified powdered ingredients as described previously (Halade et al., 2010). Primarily, we selected CO, which contains n-6 fatty acids, to underline the mechanism for bone loss along with obesity, predominantly in female mice. The standard rodent LC control diet was procured from Harlan, USA (Catalog No. Harlan Teklad LM-485 Mouse/Rat Sterilizable Diet). After completion of the 6 month period, animals from both experimental groups were sacrificed under isoflurane anesthesia. Femur bones were separated from muscle mass, stored in saline-soaked gauze at $-20^{\circ} \mathrm{C}$ until further micro-CT analysis.

\subsection{Percentage of fat mass assessed by DXA}

Body composition was measured at the beginning and at the termination of study using Dual energy X-ray Absorptiometry (DXA), using a Lunar PIXImus bone densitometer (GE, Madison, WI), as described previously (Halade et al., 2010). Percent of fat was measured using 2.10 PIXImus software.

\subsection{Quantitative structural imaging using micro-CT}

Fixed femurs were positioned within translucent foam, immersed in $70 \%$ ethanol, scanned with a SkyScan 1172 system (Kontich, Belgium). The scan parameters were as: $50 \mathrm{kV} \times \mathrm{uA}$, $20 \mathrm{~mm}$ FOV, $2048 \times 2048$ pixel matrix, 0.6 rotation step, 4 frame average, and a $10 \mu \mathrm{m}$ nominal isotropic resolution. Once the data were acquired, two volumes of interest were identified. A mid-diaphyseal volume of interest (VOI) included 100 slices centered in the mid-shaft. A second VOI was created in the distal metaphysis that included only the trabecular bone. This VOI was positioned 50 slices proximal to the distal growth plate and included 150 total slices $(1.5 \mathrm{~mm})$. Data were thresholded by visually selecting a single grey scale value that resulted in a structure that best represented original images. After thresholding, the femoral cortical bone volume (BV), relative bone volume (BV/TV) and thickness were measured in the diaphyseal VOI. In the distal femoral metaphysis, several measures including the bone volume fraction (BV/TV), structural model index (SMI), trabecular thickness $(\mathrm{TbTh})$, and trabecular number $(\mathrm{TbN})$ were calculated.

\subsection{Preparation and culture of osteoclasts from primary BM cells}

At the end of the study, BM cells were isolated from tibiae and femurs of female C57BL/6J at 18 months of age, according to the method described (Shevde et al., 2002). In brief, isolated BM cells were cultured in $\alpha$-MEM containing $10 \%$ heat-inactivated fetal calf serum 
(FCS; Invitrogen), $100 \mathrm{U} / \mathrm{ml}$ penicillin $\mathrm{G}$, and $100 \mu \mathrm{g} / \mathrm{ml}$ streptomycin at $37^{\circ} \mathrm{C}$ for $2 \mathrm{~h}$ under $95 \%$ air and 5\% CO 2. Non-adherent cells were carefully harvested, centrifuged at $2000 \mathrm{rpm}$ for $5 \mathrm{~min}$ at room temperature and viability was determined using trypan blue exclusion method. They were subsequently cultured in $\alpha$-MEM medium in 24 well plates $\left(1 \times 10^{6}\right.$ cells/ well), or phenol red-free $\alpha$-MEM in 96 -well $\left(1 \times 10^{5}\right.$ cells/well) clear-bottom white culture plates, supplemented with or without $150 \mathrm{ng} / \mathrm{ml}$ RANKL and $100 \mathrm{ng} / \mathrm{ml} \mathrm{M-CSF}$. A halfvolume of the medium, with or without RANKL/M-CSF, were replaced with the fresh medium every 3 days.

\subsection{BM tartarate-resistant acid-phosphatase (TRAP) staining}

TRAP stained BM cells were counted for multinucleated cells (MNCs), as previously described (Shevde et al., 2002). In brief, cells were fixed with $10 \%$ formalin in phosphatebuffered saline at room temperature for $15 \mathrm{~min}$. They were quenched with a 1:1 (v/v) mixture of ice-cold acetone and ethanol. These cells were incubated for $15-60 \mathrm{~min}$ at $37^{\circ} \mathrm{C}$ with $0.1 \mathrm{M}$ acetate buffer (pH 5) containing $25 \mathrm{mM}$ sodium tartrate, $0.01 \%$ naphthol ASMX phosphate, and $0.06 \%$ fast red violet LB salt and then rinsed with water. TRAPpositive, MNCs having more than three nuclei were counted as osteoclasts under microscopic observation.

\subsection{Pit formation assay}

BM cells were prepared from the femora and tibiae of 18-month-old female mice as described above. The BM cells were added to slices of sperm whale dentin. Slices of sperm whale dentin $(0.25 \times 6 \times 6 \mathrm{~mm})$ were prepared using a Buehler low-speed diamond bone saw (Buehler, Lake Bluff, IL, USA) followed by sonication (15 min) in several changes of distilled water. Slices were polished between two glass plates, transferred to petri dishes, and sterilized under UV light for 1 day. Slices were soaked in 100\% ethanol, allowed to air dry, and rinsed twice with sterile saline solution. Before all experiments, slices were incubated in $\alpha$-MEM supplemented with $10 \%$ FBS and $1 \%$ penicillin-streptomycin solution for at least $24 \mathrm{~h}$ before use. Media were removed, and $1 \times 10^{6}$ cells/well were plated in the absence or presence of $150 \mathrm{ng} / \mathrm{ml}$ recombinant murine RANKL and 100ng/ml M-CSF for 5 days in humidified air $\left(5 \% \mathrm{CO}_{2}\right)$ at $37^{\circ} \mathrm{C}$, before quantification of osteoclast numbers and assessment of resorption pit, as described by Yoneda et al. (Yoneda et al., 1995). A single experiment used 12 slices, with a minimum of 3 slices/group. Experiments were repeated at least twice on different days. For examination of resorption lacunae, the slices were sonicated in $0.1 \mathrm{M} \mathrm{NaOH}$ and stained with $0.1 \%(\mathrm{w} / \mathrm{v})$ toluidine blue. Resorption pits were counted using light microscopy, and the whole area of matrix resorbed was quantified using a computer-assisted MetaVue Image Analysis System (Olympus America Inc, PA, USA).

\subsection{Bone immunohistochemistry for RANKL and OPG expression and cytochemical analysis of TRAP}

Left femur specimens from each group were collected and trimmed of excess tissue and were fixed in 10\% neutral buffer formalin (NBF) for 48 hours at room temperature (RT). Bone specimens were decalcified in 10\% EDTA in water for 2 weeks at RT and were then placed in 70\% ETOH, processed and embedded in paraffin as detailed (Yoneda et al., 1995). RANKL (sc7628) and OPG (sc 8468) antibodies obtained from Santa Cruz Biotechnology Inc. (Santa Cruz, CA.) were used for immunostaining of paraffin-embedded bone sections following the method described by Yoneda et al. (Yoneda et al., 1995). Additional bone sections were stained cytochemically for tartrate-resistant acid phosphatase (TRAP) activity, a well-recognized marker of osteoclasts in vivo. TRAP staining of bone sections were performed as described (Oyajobi et al., 2003). RANKL, OPG and TRAP sections were digitally captured with a CoolSNAP color camera (Imaging Research St Catharines, ON, Canada) linked to an Olympus BX-40 microscope attached to a computer and MetaVue 
Bioimaging software (Universal Imaging Corp., Downingtown, PA). RANKL and OPG expression were calculated by measuring the optical density and relative area of staining, respectively. The number of TRAP+ multinucleated cells along the trabecular bone length was then enumerated and expressed as osteoclasts per millimeter of trabecular bone length ( $\mathrm{n}=5$ mice/group).

\subsection{Quantitative real-time reverse transcriptase (RT)-PCR}

Right whole femurs were crushed under liquid nitrogen conditions using a Kinematica Tissue Pulverizer and RNA was isolated using RNeasy Mini Kit following the manufacturer's instructions (Qiagen, Valencia, CA). Total RNA concentration was assessed in NanoDropTM 1000 spectrophotometer (Thermo Scientific, Wilmington, DE, USA). mRNA expression for genes encoding IL-1 $\beta$, IL-6, TNF- $\alpha$, Cathepsin K (ctsk), Runt-related transcription factor 2 (RUNX2)/ core-binding-protein-A1 (Cbfa1) and Peroxisome proliferators-activated receptor (PPAR $\gamma$ ) were measured using real time RT-PCR. Real time RT-PCR was carried out using TaqMan ${ }^{\circledR}$ RNA-to-CT 1-step kit (Applied Biosystems, Foster City, CA) in an ABI Prism 7900HT Sequence Detection System (Applied Biosystems) using fluorescent TaqMan methodology. Real time quantitative RT-PCR was performed for each of the following genes, using ready-to-use primer and probe sets predeveloped by Applied Biosystems (TaqMan Gene Expression Assays) were used to quantify IL-1 $\beta$ (Mm00434228_ml), IL-6 (Mm00466190_m1), TNF- $\alpha$ (Mm00443258_ml), ctsk (ctsk, Mm00484036_m1), RUNX2/Cbfa1 (Mm00501578_ml), PPAR $\left(\right.$ ppar $_{\gamma}, \mathrm{Mm01184321 \_ m1)}$ and Glyceraldehyde-3-phosphate dehydrogenase (Gapdh, Mm99999915_g1) as an endogenous control. mRNA Ct values for these genes were normalized to the house-keeping gene GAPDH, and expressed as relative increase or decrease to the LC group.

\subsection{Measurement of superoxide in freshly isolated BM cells, undifferentiated BM cells and differentiated osteoclasts}

The rate of superoxide production by BM cells and differentiated osteoclasts was determined using a luminol-based chemiluminescent reagent (Diogenes, National Diagnostics, GA) that is specific to superoxide (El Jamali et al., 2008). The cells were washed in PBS and placed in Hanks' balanced salt solution (HBSS). For the assay, a $100 \mu \mathrm{l}$ aliquot of the Diogenes reagent was mixed with a maximum of $1 \times 10^{5}$ cells and incubated at $37^{\circ} \mathrm{C}$ for $2-4$ minutes. Superoxide generation was stimulated with PMA $(50 \mathrm{ng} / \mathrm{ml})$ in the presence or absence of SOD $(20 \mu \mathrm{g} / \mathrm{ml})$. Chemiluminescence was measured every minute for up to 60 minutes using a microplate reader (Bio Tek; Clarity ${ }^{\mathrm{TM}}$, BioTek Instruments Inc. VT, USA) and an integration time of 5 seconds.

\section{Results}

\subsection{Increased body weight and percentage of fat in CO-fed mice as compared to LC-fed mice}

Six months of feeding a CO-enriched diet to 12-month-old C57BL/6J female mice, significantly increased body weight compared to LC (control). Consequently, CO-fed mice demonstrated significant increase in fat content (Figure 1) compared to LC-fed mice, as measured by DXA. Furthermore, the fasting serum analyses indicated a metabolic dysregulation, characterized by hyperglycemia and insulin resistance, as observed in obesity (Halade et al., 2010).

\subsection{Osteoclastogenesis is enhanced in CO-fed mice}

To further investigate whether obesity characterized by increased abdominal fat mass, total body fat mass (BFM) and BM adiposity (Halade et al., 2010) affects the BM 
microenvironment, we examined the osteoclasts formation in the BM of lean and obese mice, since bone loss is more associated with CO-fed obese mice. TRAP-positive MNCs appeared on day 3 and constituted $60-70 \%$ of total cells by day 5 . These results showed significantly increased number of TRAP-positive MNCs formed by the BM cells on plastic (Figure 2A and 2B) and dentin slice (Figure 2C and 2D) from CO-fed mice than LC-fed mice. We have previously established that $\mathrm{CO}$ developed $\mathrm{BM}$ adiposity in the femur and tibia of obese female mice (Halade et al., 2010), as compared to lean mice when fed a CO diet for 6 months. Furthermore, BM cells from CO-fed mice were able to dissolve more dentin slice area and formed more resorption pits on day 6 than LC-fed mice (Figure 2E and $2 \mathrm{~F})$. This data is consistent with our previous results on bone adiposity in obese mice (Halade et al., 2010), demonstrating increased osteoclastogenesis in BM adiposity microenvironment in obese mice than in lean mice.

\subsection{CO-fed mice exhibited reduced bone mass and trabecular micro-structure}

To address the effects of obesity-mediated bone loss, micro-CT was used to image and quantify bone mass in CO-and LC-fed mice. Representative images of distal femoral metaphysis from CO-fed mice (Figure 3B) exhibited the $66 \%$ reduction in relative trabecular bone volume (BV/TV), 20\% reduction $\mathrm{Tb}$. Th and an $83 \%$ reduction in Tb.N. than LC control mice (Figure 3C to $3 \mathrm{E}$ ). No differences were observed in the cortical bone measurements.

\subsection{CO-diet-induced obesity increased osteoclasts formation, enhanced RANKL and decreased OPG expression in femurs}

Receptor activator of nuclear factor $\mathrm{kB}$ (RANK)/RANK ligand (RANKL)/osteoprotegerin (OPG) system is an important signal transduction pathway that regulates osteoclast formation (Bai et al., 2008). Previously, we reported that CO diet-induced age-related obesity in female aging mice is associated with increased BM adiposity (Halade et al., 2010); therefore, we examined the obesity-mediated BM RANKL/OPG microenvironment in these mice. Representative histological images of bone sections (femur) demonstrated an increased number of visible adipocytes, with increased number of osteoclasts/trabecular bone length (Figure 4A and 4B), enhanced expression of RANKL (Figure 5A and 5B) and decreased expression of OPG (Figure 6A and 6B) in CO-fed obese mice compared with their LC control counterparts. These results indicate that $\mathrm{CO}$ diet induces osteoclastogenesis.

\subsection{CO diet reduced osteoblast specific and increased adipocyte, osteoclast-specific and pro-inflammatory gene expression in femurs}

Gene expression was assessed using real time RT-PCR to determine the status of bone homeostasis. Our data show that $\mathrm{CO}$ diet induces the expression of gene associated with BM adiposity-mediated inflammation (Figure 7A, 7B, and 7C). Furthermore, PPAR $\gamma$, a known marker of adipocyte differentiation and maturation, were significantly elevated in CO-fed mice compared to LC (Figure 7D). These data are consistent with enhanced BM adiposity and related inflammation by $\mathrm{CO}$ diet. Moreover, increased mRNA levels of cathepsin $\mathrm{k}$, an osteoclast marker gene (Figure 7E), and reduced levels of RUNX2/Cbfa1 (Figure 7F), an early marker of osteoblasts, indicate lineage selection towards osteoclast differentiation in inflammatory BM adiposity conditions. Suppression of osteoblast-specific mRNA levels, and enhanced osteoclast-specific and inflammatory gene expression is consistent with increased bone adiposity and decreased bone density in female obese mice.

\subsection{Obese mice generated more superoxide in osteoclasts and BM cells}

We examined superoxide production in freshly isolated BM cells. As described previously, we found that these cells transiently produce superoxide when stimulated by PMA. A 
maximum is reached very rapidly $(<5 \mathrm{~min})$, followed by a plateau $(5-20 \mathrm{~min})$ and a slow decrease to reach non-stimulated levels $(60 \mathrm{~min})$. In freshly isolated BM cells, superoxide production stimulated by PMA was not significantly affected by the diet (Figure 8A and 8B). In absence of RANKL, we observed that BM cells culture obtained from CO-fed mice conserved the ability to produce superoxide when stimulated with PMA. The kinetic was however different since a maximum was reached in $30 \mathrm{~min}$ and was sustained for the next 30 min (Figure 8C and 8D). Finally, we tested superoxide production by BM cells cultured in the presence of RANKL to induce their differentiation in osteoclasts. Stimulation of osteoclasts obtained from both CO-fed mice and LC-fed mice by PMA transiently induced superoxide production (Figure 8E and 8F). A maximum signal was reached in 30 min and superoxide production returned to basal level $30 \mathrm{~min}$ later. The level of superoxide produced by osteoclast obtained from CO-fed mice was significantly higher than levels produced by osteoclasts obtained by LC-fed mice. Furthermore, for all conditions tested, chemiluminescence detected by the Diogenes ${ }^{\circledR}$ reagent was abrogated by the addition of superoxide dismutase (SOD), indicating that generation of superoxide anion was being specifically detected. These results show collectively that CO-diet increases superoxide production by osteoclasts and undifferentiated BM cells.

\section{Discussion}

Clinical evidence of obesity in older adults is associated with bone loss (McTigue et al., 2006) and indicates that controlling fat accumulation is an important target for skeletal health (Kawai et al., 2009; Kawai and Rosen). In addition, several reports demonstrate that obesity is negatively associated with bone mass (Nunez et al., 2007) in boys (10-12 years) (Dimitri et al., 2009), in girls (12-18 years) (Russell et al.), men (25-45 years) (Taes et al., 2009) and adolescent women (15-25 years) (Gilsanz et al., 2009). It seems that obesity is a common factor in bone loss. Consistent with our previous findings (Halade et al., 2010), we have clearly demonstrated: (i) obesity in female mice is accompanied by increased bone resorption and reduced bone mass; (ii) change in fat metabolism, like increased obesity, affects skeletal health by stimulating osteoclastogenesis in the BM microenvironment; (iii) adipose tissue acts as an endocrine organ, secreting pro-inflammatory cytokines (such as IL-1 $\beta$ and IL-6), TNF- $\alpha$, and adipokines, whose effects are detrimental to the trabecular skeleton; and (iv) superoxide production is associated with obesity-mediated bone resorption.

Our results are consistent with the idea that fat accumulation itself in the BM microenvironement is responsible for poor skeleton health (Kawai and Rosen; Naveiras et al., 2009), and induces a shift from bone formation to bone resorption, due to lipotoxicity (Duque, 2008). Two concepts are widely accepted: i) that fat overload would replace functional hematopoietic and/or osteogenic cells in the BM cavity (Naveiras et al., 2009); and ii) that a balanced BM microenvironment is critical for normal osteogenesis, among other processes (Naveiras et al., 2009). Increased production of adipocytes and related factors, cytokines and fatty acids, could alter the fat-BM relationship, thereby inhibiting osteogenesis (Naveiras et al., 2009).

PPAR $\gamma$ is a critical transcription factor in adipogenesis of the nuclear receptor super family (Takada et al., 2009), which is activated by thiazolidinedione compounds (Grey, 2009).

Activation of PPAR $\gamma$ stimulates adipogenesis and inhibits osteogenesis (David et al., 2007), as they share a common progenitor, i.e., MSC in the BM (Pittenger et al., 1999). Previously, we noted increased mRNA expression of PPAR $\gamma$ in the BM of CO-fed obese mice, demonstrated by increased BM adiposity (Halade et al., 2010). In the present investigation, we showed that enhanced PPAR $\gamma$ may inhibit the transcription factor RUNX2/cbfa1, which is indispensable for osteoblast differentiation (Ducy et al., 1997). Previous studies have also 
shown that BM adipogenesis increased lipopolysaccharide-stimulated pro-inflammatory cytokines IL-6 and TNF- $\alpha$, secreted by the BM (Halade et al., 2010) in CO-fed mice, further demonstrating an elevated mRNA expression of pro-inflammatory IL-1 $\beta$, IL- 6 and TNF- $\alpha$ cytokines. These cytokines have been shown to increase osteoclast activity through regulation of the RANKL/RANK/OPG pathway (Khosla, 2001). Moreover, CO-fed mice exhibited an increase ctsk mRNA expression, which is a collagenolytic, papain-like, cysteine protease that is mainly expressed in osteoclasts, functioning in the bone resorptive process (Deaton and Tavares, 2005). Furthermore, knockout studies of ctsk in mice lead to an osteopetrotic phenotype (Bromme and Lecaille, 2009). Taken together, our results show that $\mathrm{CO}$ induces up-regulation of PPAR $\gamma$ and down-regulation of RUNX2/cbfa1, which leads to BM adiposity. This altered microenvironment, with increased ctsk and inflammatory cytokines, possibly contributes to bone resorption in these obese mice.

It is widely accepted that three major processes lead to age-related osteoporosis. The first and most important is trabecular bone loss, the second process is continued bone resorption at the endocortical surface and the third is a decrease of cortical bone (Chen et al., 2009). Our present investigation illustrated that the most prominent change in obesity-mediated bone loss was the decrease of trabecular bone within the femur. Some limitations of this current study should be mentioned. First of all, a limited number of skeletal sites were analyzed. With more specimens from the femoral neck, tibia and thoracic vertebra, we may offer more suitable conclusions on the site-dependent variations of the bone microstructural properties. A second limitation is that serum concentrations of bone remodeling markers, such as osteocalcin, TRAP, alkaline phosphatase and insulin like growth factor-1, were not measured in the present investigation. Other studies have shown that significant reductions in serum IGF-1 levels are also associated with aging (Niu and Rosen, 2005). Evidence suggests that high circulating concentrations of leptin in obesity can stimulate skeletal growth (Maor et al., 2002). Recently, Cao et al. reported increased serum TRAP and decreased concentration of osteocalcin in high-fat fed mice (Cao et al., 2010). Despite the limitations of present study, an inverse correlation is indicated between the obesity-mediated inflammatory BM microenvironment and the trabecular bone microstructural parameters which contribute to bone resorption in obesity.

In accord with those studies and consistent with the recently published study by Patsch et al, and Cao et al. showing that obesity resulted in significant bone loss, particularly in the trabecular architecture in young C57BL/6J male mice (Cao et al., 2009; Patsch et al.). Agerelated bone loss is characteristic of both male and female C57BL/6J mice (Glatt et al., 2007); therefore, both CO and LC have absolutely low relative bone volume (BV/TV) due to age, noting the accelerated trabecular bone loss in CO-fed mice. Our study is distinguished by its emphasis on a model of a westernized diet-induced obesity and inflammatory bone resorption. It provides insight to resolve the question of how much fat deposition in the BM is safe with aging in females. It is also be worth mentioning that $\mathrm{BM}$ fat and bone mass are not always inversely proportional. For example, the $\mathrm{C} 3 \mathrm{H} / \mathrm{HeJ}$ mouse strain has both high BM adiposity and high BMD (Rosen, 2008). Eventually, exact thresholds of BM adiposity with aging in obesity need to be investigated. Obesity also leads to type 2 diabetes, a factor of the metabolic syndrome, which consistently demonstrates increased BMD, but compromised bone strength in men (Petit et al., 2009). In addition, postmenopausal obese women, thought to be at high risk for fracture (Premaor et al., 2009) and knee osteoarthritis (Sowers and Karvonen-Gutierrez), exhibit this same trend. Currently, the precise mechanism for musculoskeletal complications in obesity is unclear; here, we provide a compelling rationale to investigate these mechanisms in greater detail.

Aging leads to changes in body composition and fat distribution that have negative effects on bone mass and health (Kuk et al., 2009). Aging results in a preferential shift to 
adipogenesis, among osteoblast precursor cells (Duque and Troen, 2008). Therefore, it is conceivable that a certain fat accumulation to be beneficial to bone homeostasis and that excess of fat over an undefined threshold would decrease bone mass. It might be either an independent factor or might be a cofounding factor contributing to bone loss in obesity phenotype.

Obesity-mediated change in fat metabolism impacts skeletal health by stimulating osteoclastogenesis in the BM microenvironment. Bone resorption and formation are linked through the RANK/RANKL/OPG axis (Bai et al., 2008; Khosla, 2001). The activation of the receptor for RANKL (RANK) is a key step in the differentiation into mature osteoclasts (Feng, 2005; Yasuda et al., 1998) and an endogenous antagonist of RANKL is osteoprotegerin (OPG), also known as osteoclastogenesis inhibitory factor (OCIF), which inhibits the production of osteoclasts by blocking the RANKL-RANK interaction. In accord with those previous findings (Cao et al., 2003; Cao et al., 2010; Kyung et al., 2009), we observed that CO-induced osteoclastogenesis correlates with an increase of RANKL (Figure 5 ) and a decrease of OPG (Figure 6). These results suggest that a CO diet may contribute to bone loss, through the modulation of RANK/RANKL/OPG axis in favor of osteoclastogenesis,

Of interest, we observed that a CO diet increases ROS production in undifferentiated BM cells and osteoclasts. Since the stimulation of osteoclast formation by RANKL generates reactive oxygen species (ROS) through Nox enzymes (Lee et al., 2005), it is possible that a CO-enriched diet alters Nox activity or expression, thereby, contributing to oxidative stressmediated bone resorption. Nox1, Nox2, and Nox4 enzymes are expressed in osteoclasts and their precursor cells. While the role of Nox-dependent ROS production is found to be necessary for the differentiation of monocyte/macrophage lineage cells into osteoclasts, the exact role and contribution of the different Nox remains unclear (Sasaki et al., 2009). The fact that the effect of a $\mathrm{CO}$ diet is prominent in undifferentiated cells suggests that macrophages, which are the immediate precursor of the osteoclast, are possibly directly affected by the diet. These results suggest that a $\mathrm{CO}$ diet may alter hematopoiesis. However it remains to be determined which BM cell populations are affected by the diet, how they are affected and which Nox enzymes might be contributing to this CO-induced osteoclastogenesis.

In summary, our results questioned the traditional dogma that obesity increases bone mass (Wardlaw, 1996) and adipocytes act as inactive fillers in the BM. We showed that obesity enhanced osteoclastogenesis and reduced osteoblast formation affecting overall bone homeostasis in favor of bone resorption (Figure 9). Furthermore, our results suggest a plausible mechanism where the accumulation of adipocytes in the BM may increase inflammation and bone resorption in a redox-dependent manner. Future detailed mechanistic studies in this innovative area are necessary to identify the complex molecular pathways involved in BM adipogenesis and osteoporosis progression.

\section{Acknowledgments}

The authors would like to thank Nishu Kazi for her assistance in diet preparation, animal care and feeding the animals. GF is supported by NIH grants 1R01AT004259-01 and 1R01AG030161-01A1.

\section{Abbreviations}

$\begin{array}{ll}\text { AIN } & \text { American Institute of Nutrition } \\ \text { BM } & \text { Bone marrow }\end{array}$




$\begin{array}{ll}\text { BMC } & \text { Bone marrow cells } \\ \text { BV/TV } & \text { Relative bone volume } \\ \text { Cbfa } & \text { Core-binding-protein-A1 } \\ \text { CO } & \text { Corn oil } \\ \text { DXA } & \text { Dual energy X-ray Absorptiometry } \\ \text { IL } & \text { Interleukin } \\ \text { LC } & \text { Lab chow } \\ \text { Micro-CT } & \text { Micro-computer tomography } \\ \text { OPG } & \text { Osteoprotegerin } \\ \text { PPAR } & \text { Peroxisome proliferators-activated receptor } \\ \text { PMA } & \text { Phorbol 12-myristate 13-acetate } \\ \text { RANKL } & \text { Receptor activator of nuclear factor-k } \beta \text { ligand } \\ \text { ROS } & \text { Reactive oxygen species } \\ \text { RT-PCR } & \text { Reverse transcriptase polymerase chain reaction } \\ \text { RUNX2 } & \text { Runt-related transcription factor 2 } \\ \text { SOD } & \text { Superoxide dismutase } \\ \text { TNF } & \text { Tumor necrosis factor } \\ \text { TRAP } & \text { Tartarate-resistant acid-phosphatase } \\ \text { VOI } & \text { volume of interest } \\ & \end{array}$

\section{References}

Kopelman PG. Obesity as a medical problem. Nature 2000;404:635-43. [PubMed: 10766250]

Ogden CL, Carroll MD, Curtin LR, McDowell MA, Tabak CJ, Flegal KM. Prevalence of overweight and obesity in the United States, 1999-2004. JAMA 2006;295:1549-55. [PubMed: 16595758]

Powell K. Obesity: the two faces of fat. Nature 2007;447:525-7. [PubMed: 17538594]

Kirchengast S, Knogler W, Hauser G. Protective effect of moderate overweight on bone density of the hip joint in elderly and old Austrians. Anthropol Anz 2002;60:187-97. [PubMed: 12161964]

Villareal DT, Apovian CM, Kushner RF, Klein S. Obesity in older adults: technical review and position statement of the American Society for Nutrition and NAASO, The Obesity Society. Am J Clin Nutr 2005;82:923-34. [PubMed: 16280421]

Ehrlich PJ, Lanyon LE. Mechanical strain and bone cell function: a review. Osteoporos Int 2002;13:688-700. [PubMed: 12195532]

Bonewald LF, Johnson ML. Osteocytes, mechanosensing and Wnt signaling. Bone 2008;42:606-15. [PubMed: 18280232]

Nunez NP, Carpenter CL, Perkins SN, Berrigan D, Jaque SV, Ingles SA, Bernstein L, Forman MR, Barrett JC, Hursting SD. Extreme obesity reduces bone mineral density: complementary evidence from mice and women. Obesity (Silver Spring) 2007;15:1980-7. [PubMed: 17712115]

Rosen CJ, Bouxsein ML. Mechanisms of disease: is osteoporosis the obesity of bone? Nat Clin Pract Rheumatol 2006;2:35-43. [PubMed: 16932650]

Zhao LJ, Jiang H, Papasian CJ, Maulik D, Drees B, Hamilton J, Deng HW. Correlation of obesity and osteoporosis: effect of fat mass on the determination of osteoporosis. J Bone Miner Res 2008;23:17-29. [PubMed: 17784844] 
Duque G. Bone and fat connection in aging bone. Curr Opin Rheumatol 2008;20:429-34. [PubMed: 18525356]

Mundy GR. Osteoporosis and inflammation. Nutr Rev 2007;65:S147-51. [PubMed: 18240539]

Naveiras O, Nardi V, Wenzel PL, Hauschka PV, Fahey F, Daley GQ. Bone-marrow adipocytes as negative regulators of the haematopoietic microenvironment. Nature 2009;460:259-63. [PubMed: 19516257]

Oh SR, Sul OJ, Kim YY, Kim HJ, Yu R, Suh JH, Choi HS. Saturated fatty acids enhance osteoclast survival. J Lipid Res 2010;51:892-9. [PubMed: 20388920]

Horowitz MC, Xi Y, Wilson K, Kacena MA. Control of osteoclastogenesis and bone resorption by members of the TNF family of receptors and ligands. Cytokine Growth Factor Rev 2001;12:9-18. [PubMed: 11312114]

Wu D, Ren Z, Pae M, Guo W, Cui X, Merrill AH, Meydani SN. Aging up-regulates expression of inflammatory mediators in mouse adipose tissue. J Immunol 2007;179:4829-39. [PubMed: 17878382]

Boyle WJ, Simonet WS, Lacey DL. Osteoclast differentiation and activation. Nature 2003;423:33742. [PubMed: 12748652]

Key LL Jr. Wolf WC, Gundberg CM, Ries WL. Superoxide and bone resorption. Bone 1994;15:431-6. [PubMed: 7917583]

Wauquier F, Leotoing L, Coxam V, Guicheux J, Wittrant Y. Oxidative stress in bone remodelling and disease. Trends Mol Med 2009;15:468-77. [PubMed: 19811952]

Simopoulos AP. Evolutionary aspects of diet, the omega-6/omega-3 ratio and genetic variation: nutritional implications for chronic diseases. Biomed Pharmacother 2006;60:502-7. [PubMed: 17045449]

Halade GV, Rahman MM, Williams PJ, Fernandes G. High fat diet-induced animal model of ageassociated obesity and osteoporosis. J Nutr Biochem. 2010 In press.

Shevde NK, Plum LA, Clagett-Dame M, Yamamoto H, Pike JW, DeLuca HF. A potent analog of 1alpha,25-dihydroxyvitamin D3 selectively induces bone formation. Proc Natl Acad Sci U S A 2002;99:13487-91. [PubMed: 12374862]

Yoneda T, Williams P, Rhine C, Boyce BF, Dunstan C, Mundy GR. Suramin suppresses hypercalcemia and osteoclastic bone resorption in nude mice bearing a human squamous cancer. Cancer Res 1995;55:1989-93. [PubMed: 7728770]

Oyajobi BO, Franchin G, Williams PJ, Pulkrabek D, Gupta A, Munoz S, Grubbs B, Zhao M, Chen D, Sherry B, Mundy GR. Dual effects of macrophage inflammatory protein-1alpha on osteolysis and tumor burden in the murine 5TGM1 model of myeloma bone disease. Blood 2003;102:311-9. [PubMed: 12649140]

El Jamali A, Valente AJ, Lechleiter JD, Gamez MJ, Pearson DW, Nauseef WM, Clark RA. Novel redox-dependent regulation of NOX5 by the tyrosine kinase c-Abl. Free Radic Biol Med 2008;44:868-81. [PubMed: 18160052]

Bai YD, Yang FS, Xuan K, Bai YX, Wu BL. Inhibition of RANK/RANKL signal transduction pathway: a promising approach for osteoporosis treatment. Med Hypotheses 2008;71:256-8. [PubMed: 18445511]

McTigue KM, Hess R, Ziouras J. Obesity in older adults: a systematic review of the evidence for diagnosis and treatment. Obesity (Silver Spring) 2006;14:1485-97. [PubMed: 17030958]

Kawai M, Devlin MJ, Rosen CJ. Fat targets for skeletal health. Nat Rev Rheumatol 2009;5:365-72. [PubMed: 19468288]

Kawai M, Rosen CJ. Bone: adiposity and bone accrual-still an established paradigm? Nat Rev Endocrinol 2010;6:63-4. In press. [PubMed: 20098443]

Dimitri P, Wales J, Bishop N. Fat and Bone in Children - Differential Effects of Obesity on Bone Size and Mass According to Fracture History. J Bone Miner Res. 2009

Russell M, Mendes N, Miller KK, Rosen CJ, Lee H, Klibanski A, Misra M. Visceral Fat Is a Negative Predictor of Bone Density Measures in Obese Adolescent Girls. J Clin Endocrinol Metab. 2010 In press.

Exp Gerontol. Author manuscript; available in PMC 2012 January 1. 
Taes YE, Lapauw B, Vanbillemont G, Bogaert V, De Bacquer D, Zmierczak H, Goemaere S, Kaufman JM. Fat mass is negatively associated with cortical bone size in young healthy male siblings. J Clin Endocrinol Metab 2009;94:2325-31. [PubMed: 19401374]

Gilsanz V, Chalfant J, Mo AO, Lee DC, Dorey FJ, Mittelman SD. Reciprocal relations of subcutaneous and visceral fat to bone structure and strength. J Clin Endocrinol Metab 2009;94:3387-93. [PubMed: 19531595]

Takada I, Kouzmenko AP, Kato S. Molecular switching of osteoblastogenesis versus adipogenesis: implications for targeted therapies. Expert Opin Ther Targets 2009;13:593-603. [PubMed: 19397478]

Grey A. Thiazolidinedione-induced skeletal fragility--mechanisms and implications. Diabetes Obes Metab 2009;11:275-84. [PubMed: 18671797]

David V, Martin A, Lafage-Proust MH, Malaval L, Peyroche S, Jones DB, Vico L, Guignandon A. Mechanical loading down-regulates peroxisome proliferator-activated receptor gamma in bone marrow stromal cells and favors osteoblastogenesis at the expense of adipogenesis. Endocrinology 2007;148:2553-62. [PubMed: 17317771]

Pittenger MF, Mackay AM, Beck SC, Jaiswal RK, Douglas R, Mosca JD, Moorman MA, Simonetti DW, Craig S, Marshak DR. Multilineage potential of adult human mesenchymal stem cells. Science 1999;284:143-7. [PubMed: 10102814]

Ducy P, Zhang R, Geoffroy V, Ridall AL, Karsenty G. Osf2/Cbfa1: a transcriptional activator of osteoblast differentiation. Cell 1997;89:747-54. [PubMed: 9182762]

Khosla S. Minireview: the OPG/RANKL/RANK system. Endocrinology 2001;142:5050-5. [PubMed: 11713196]

Deaton DN, Tavares FX. Design of cathepsin K inhibitors for osteoporosis. Curr Top Med Chem 2005;5:1639-75. [PubMed: 16375747]

Bromme D, Lecaille F. Cathepsin K inhibitors for osteoporosis and potential off-target effects. Expert Opin Investig Drugs 2009;18:585-600.

Chen H, Zhou X, Emura S, Shoumura S. Site-specific bone loss in senescence-accelerated mouse (SAMP6): a murine model for senile osteoporosis. Exp Gerontol 2009;44:792-8. [PubMed: 19815059]

Niu T, Rosen CJ. The insulin-like growth factor-I gene and osteoporosis: a critical appraisal. Gene 2005;361:38-56. [PubMed: 16183214]

Maor G, Rochwerger M, Segev Y, Phillip M. Leptin acts as a growth factor on the chondrocytes of skeletal growth centers. J Bone Miner Res 2002;17:1034-43. [PubMed: 12054158]

Cao JJ, Sun L, Gao H. Diet-induced obesity alters bone remodeling leading to decreased femoral trabecular bone mass in mice. Ann N Y Acad Sci 2010;1192:292-7. [PubMed: 20392249]

Cao JJ, Gregoire BR, Gao H. High-fat diet decreases cancellous bone mass but has no effect on cortical bone mass in the tibia in mice. Bone 2009;44:1097-104. [PubMed: 19264159]

Patsch JM, Kiefer FW, Varga P, Pail P, Rauner M, Stupphann D, Resch H, Moser D, Zysset PK, Stulnig TM, Pietschmann P. Increased bone resorption and impaired bone microarchitecture in short-term and extended high-fat diet-induced obesity. Metabolism. 2010 In press.

Glatt V, Canalis E, Stadmeyer L, Bouxsein ML. Age-related changes in trabecular architecture differ in female and male C57BL/6J mice. J Bone Miner Res 2007;22:1197-207. [PubMed: 17488199]

Rosen CJ. Bone remodeling, energy metabolism, and the molecular clock. Cell Metab 2008;7:7-10. [PubMed: 18177720]

Petit MA, Paudel ML, Taylor BC, Hughes JM, Strotmeyer ES, Schwartz AV, Cauley JA, Zmuda JM, Hoffman AR, Ensrud KE. Bone Mass and Strength in Older Men with Type 2 Diabetes: The Osteoporotic Fractures in Men Study. J Bone Miner Res. 2009

Premaor MO, Pilbrow L, Tonkin C, Parker R, Compston J. Obesity and Fractures in Postmenopausal Women. J Bone Miner Res. 2009 In press.

Sowers MR, Karvonen-Gutierrez CA. The evolving role of obesity in knee osteoarthritis. Curr Opin Rheumatol 2010;22:533-7. In press. [PubMed: 20485173]

Kuk JL, Saunders TJ, Davidson LE, Ross R. Age-related changes in total and regional fat distribution. Ageing Res Rev 2009;8:339-48. [PubMed: 19576300] 
Duque G, Troen BR. Understanding the mechanisms of senile osteoporosis: new facts for a major geriatric syndrome. J Am Geriatr Soc 2008;56:935-41. [PubMed: 18454751]

Feng X. Regulatory roles and molecular signaling of TNF family members in osteoclasts. Gene 2005;350:1-13. [PubMed: 15777737]

Yasuda H, Shima N, Nakagawa N, Yamaguchi K, Kinosaki M, Mochizuki S, Tomoyasu A, Yano K, Goto M, Murakami A, Tsuda E, Morinaga T, Higashio K, Udagawa N, Takahashi N, Suda T. Osteoclast differentiation factor is a ligand for osteoprotegerin/osteoclastogenesis-inhibitory factor and is identical to TRANCE/RANKL. Proc Natl Acad Sci U S A 1998;95:3597-602. [PubMed: 9520411]

Cao J, Venton L, Sakata T, Halloran BP. Expression of RANKL and OPG correlates with age-related bone loss in male C57BL/6 mice. J Bone Miner Res 2003;18:270-7. [PubMed: 12568404]

Kyung TW, Lee JE, Phan TV, Yu R, Choi HS. Osteoclastogenesis by bone marrow-derived macrophages is enhanced in obese mice. J Nutr 2009;139:502-6. [PubMed: 19176752]

Lee NK, Choi YG, Baik JY, Han SY, Jeong DW, Bae YS, Kim N, Lee SY. A crucial role for reactive oxygen species in RANKL-induced osteoclast differentiation. Blood 2005;106:852-9. [PubMed: 15817678]

Sasaki H, Yamamoto H, Tominaga K, Masuda K, Kawai T, Teshima-Kondo S, Matsuno K, YabeNishimura C, Rokutan K. Receptor activator of nuclear factor-kappaB ligand-induced mouse osteoclast differentiation is associated with switching between NADPH oxidase homologues. Free Radic Biol Med 2009;47:189-99. [PubMed: 19409483]

Wardlaw GM. Putting body weight and osteoporosis into perspective. Am J Clin Nutr 1996;63:433S436S. [PubMed: 8615336] 
A

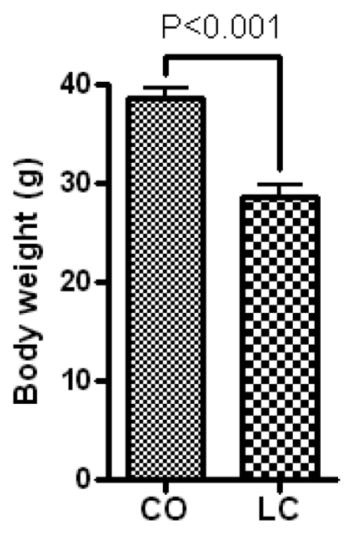

B

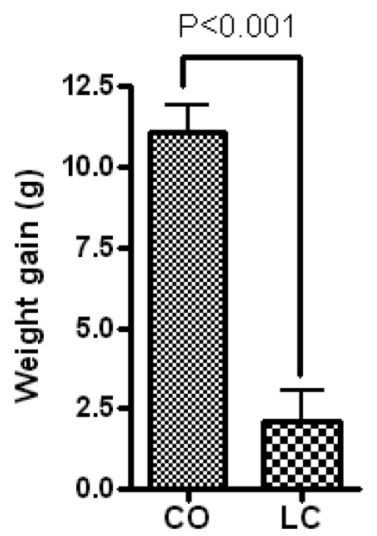

C

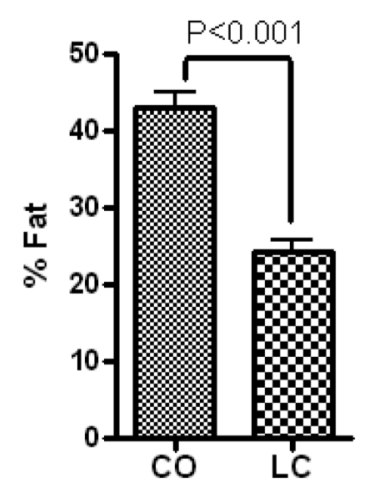

Figure 1.

CO-fed mice increased body weight (g) and \% fat, compared to standard diet-fed mice (LC) measured by DXA. (A) Body weight, (B) Body weight gain, and (C) \% fat. All measurements were performed in 18 -month-old C57BL/6J female mice $(n=10)$ fed with $\mathrm{CO}$ or LC for 6 months. Data are mean \pm SEM. Results were analyzed by t-test (unpaired) and $p$ $<0.05$ was considered significant. 
A

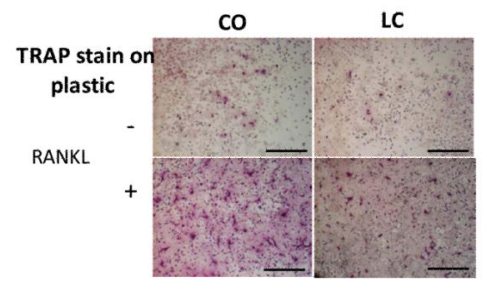

C

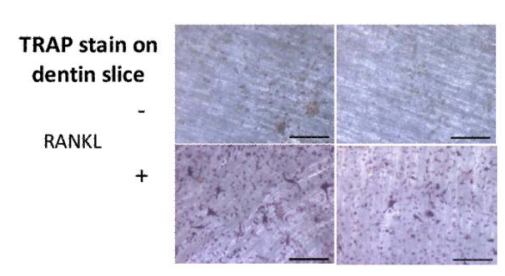

$\mathbf{E}$
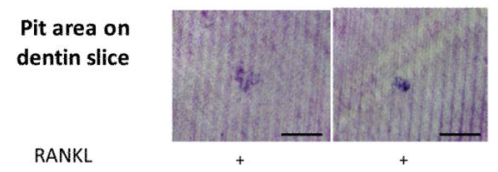

B

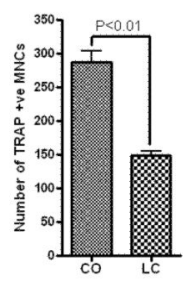

D
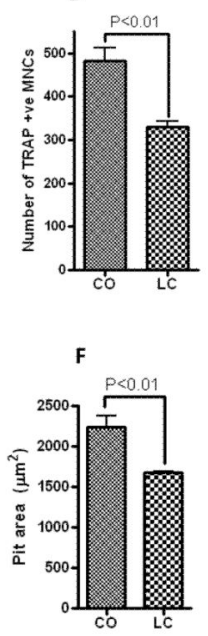

Figure 2.

Osteoclastogenesis from BM cells of corn oil (CO)-and LC-fed female C57BL/6J mice. BM cells from 12-month-old $\mathrm{C} 57 \mathrm{Bl} / 6 \mathrm{~J}$ fed with $\mathrm{LC}$ or $\mathrm{CO}$ for 6 months were cultured with or without $150 \mathrm{ng} / \mathrm{ml} \mathrm{RANKL}$ and $100 \mathrm{ng} / \mathrm{ml} \mathrm{M-CSF}$ for 6 days. Half of the medium was replaced with fresh medium every 3 days. These cells were fixed and stained with TRAP on day 6. Numbers of TRAP-positive, multinucleated cells containing three or more nuclei were counted. Values are means \pm SEM of three independent experiments. (A) TRAP on plastic plate, (B) Number of TRAP+ MNCs on plastic, (C) TRAP on dentin slice, (D) Number of TRAP+ MNCs on dentin slice, (E) Resorption pits and (F) Pit area $\left(\mu \mathrm{m}^{2}\right)$ that formed were measured, after the BM cells were cultured with or without $150 \mathrm{ng} / \mathrm{ml}$ RANKL and $100 \mathrm{ng} / \mathrm{ml} \mathrm{MCSF}$ for 6 days. After removal of the cells, the thin films and the dentine slices stained with $0.5 \%$ toludine blue and were photographed. Values are means \pm SEM of two independent experiments analyzed by t-test (unpaired). Scale bar in (A), (C) and $(\mathrm{E})$ are $650 \mu \mathrm{m}$. 


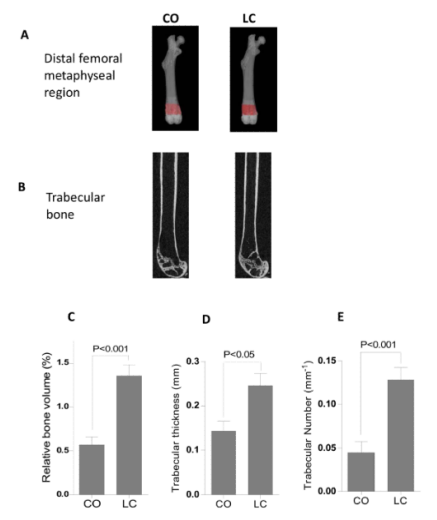

Figure 3.

Structural parameters of trabecular bone in the distal femoral metaphysis in mice fed the CO and the LC diet. (A) The figures illustrate the region in the mouse femur analyzed by $\mu C T$. (B) Gray-scale image showing the amounts of trabecular bone in the distal femurs. An evaluation of trabecular bone structural parameters was done in a region of interest that consisted of 100 slices starting from approximately $0.1 \mathrm{~mm}$ distal to growth plate, constituting $0.72 \mathrm{~mm}$ in length. (C) Relative bone volume (BV/TV), (D) Trabecular thickness (TbTh), and (E) Trabecular number $(\mathrm{TbN})$. Data are mean \pm SEM (n=6). Results were analyzed by t-test (unpaired) and $\mathrm{p}<0.05$ was considered significant. 
A

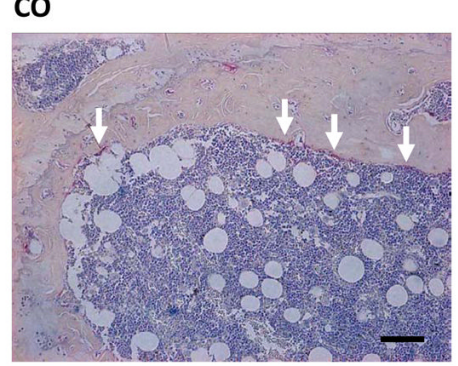

LC

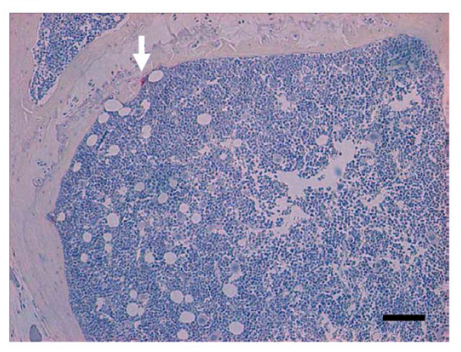

B

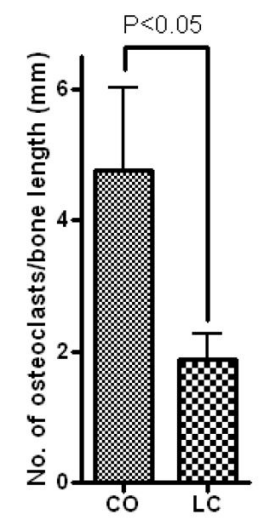

Figure 4.

Femural sections for TRAP activity illustrate clear differences in osteoclast number. TRAP +ve staining for osteoclasts in femur of 12 -month-old female C57BL/6J mice fed with CO and LC for 6 months. Note overall increased number of osteoclasts along the trabecular bone surface in CO-fed mice (left panel) compared with LC-fed mice (right panel). All sections were counterstained with Haematoxylin ( $n=5)$. Original magnification is 10X. (A) TRAP+ multinucleated osteoclasts aligned the trabecular bone length (Upper panel), (B) Number of osteoclasts per millimeter of trabecular bone length (Lower panel). Scale bar in (A) is 125 $\mu \mathrm{m}$. Results were analyzed by t-test (unpaired) and $\mathrm{p}<0.05$ was considered significant. 
A
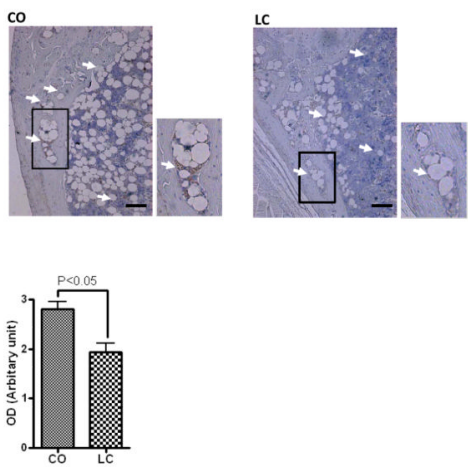

Figure 5 .

Immunohistochemical staining for RANKL protein expression (DAB) in 12-month-old female C57BL/6J mice fed with CO or LC for 6 months. All sections were counterstained with Haematoxylin $(n=5)$. (A) Higher RANKL protein demonstrated in femur of CO-fed mice using immunostaining (white arrows) compared to standard diet-fed mice (LC). (B) Optical density of staining on 5 individual mouse femurs. Scale bar in (A) is $125 \mu \mathrm{m}$. Results were analyzed by t-test (unpaired) and $\mathrm{p}<0.05$ was considered significant. 
A

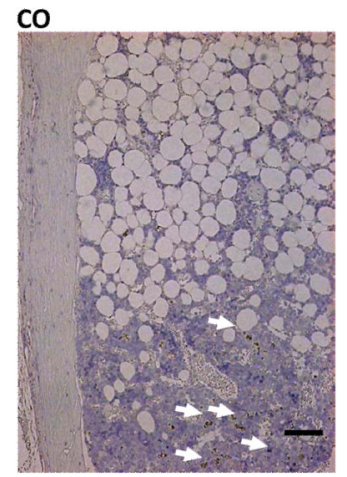

B

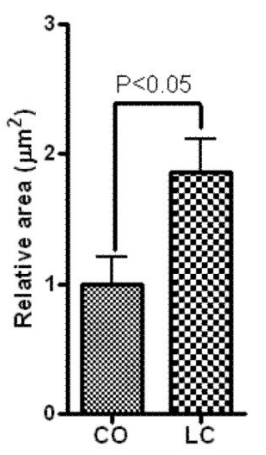

LC

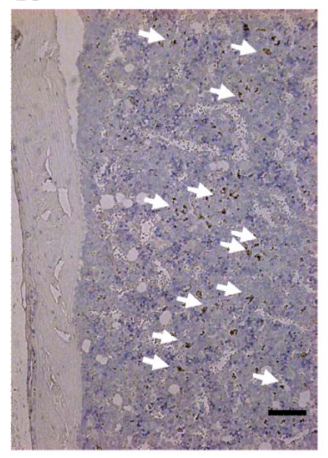

Figure 6.

OPG staining is more prominent in LC than CO-fed mice in the bone microenvironment, particularly in bone marrow. (A) Representative images of immunohistochemical staining for OPG in 12 months old female C57BL/6J mice fed with CO or LC for 6 months. All samples were counterstained with Haematoxylin $(n=5)$. OPG staining (DAB) in cells within bone marrow remote from bone demonstrating strong expression of OPG in numerous cells in LC-fed mice than CO-fed mice. (B) Relative area of staining on 5 individual mouse femurs. Scale bar in (A) is $125 \mu \mathrm{m}$. Results were analyzed by t-test (unpaired) and $\mathrm{p}<0.05$ was considered significant. 


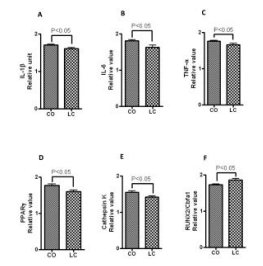

Figure 7.

Gene expression of inflammatory cytokines (IL-1 $\beta$, IL-6 and TNF- $\alpha$ ), osteoclasts, osteoblasts and adipocytes specific mRNAs in CO-and LC-fed mice. RNAs were isolated from femur of 18 month-old C57BL/6J female mice fed $\mathrm{CO}$ or LC for 6 months. Transcript levels of (A) IL-1 $\beta$, (B) IL-6 and (C) TNF- $\alpha$, (D) PPAR $\gamma$, (E) cathepsin K , and (F) RUNX2/ Cbfa1 were measured by real-time RT-PCR using GAPDH mRNA level as an internal quantity control. Values are means $\pm \operatorname{SEM}(n=5)$. Statistical significance $(\mathrm{P}<0.05)$ was measured CO vs LC-fed mice using student's t-test (unpaired). 
A

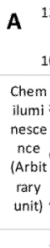

c

C 12

$\begin{array}{ll} & 10 \\ \text { Chem } & \\ \text { illumi } & 8 \\ \text { nesce } & 8 \\ \text { nce } \\ \text { (Arbit } & 6 \\ \text { rary } \\ \text { unit) } & 4\end{array}$

(2)

E

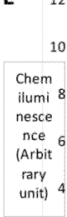

Time (hr:min:sec)

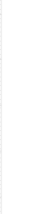
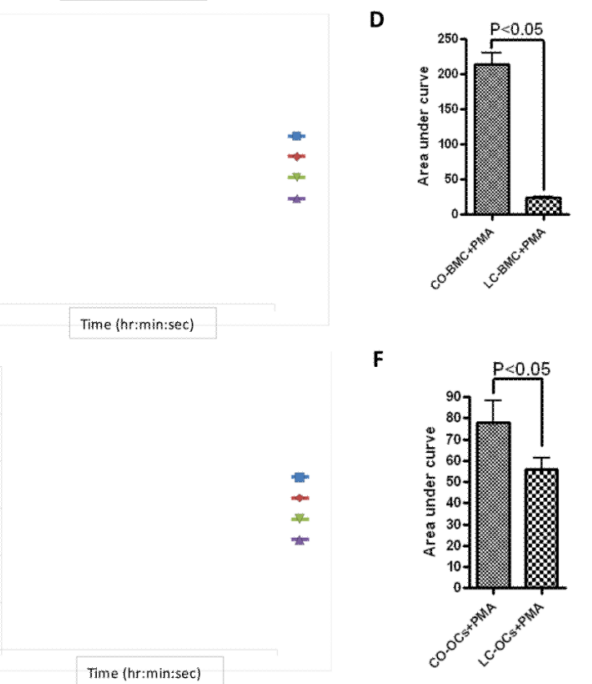

Figure 8.

Spontaneous (Diamond, triangle) or $50 \mathrm{ng} / \mathrm{ml}$ PMA-stimulated (square, $\mathrm{x}$ ) superoxide production was determined in freshly isolated bone marrow cells $(\mathrm{A}, \mathrm{B})$, undifferentiated bone marrow cells (C, D) and osteoclasts (E, F) obtained from 18-month old female C57BL/ $6 \mathrm{~J}$ mice fed with $\mathrm{CO}$ and LC diet. (A, C, E) Chemiluminescence output of the cells incubated or not with PMA for the indicated times. (B, D, F) Superoxide production was calculated as the area under the curve after the normalization by the subtraction of the zerotime value of the chemiluminescence output. The data expressed are the means $+/-$ SEM of 3 independent experiments. Statistical significance versus cells obtained from LC-fed mice is indicated ( $\mathrm{p}<0.05)$. BMC: bone marrow cells, CO: corn oil, LC: Lab chow (standard diet), OCs: Osteoclasts, PMA: Phorbol 12-myristate 13-acetate, SOD: Superoxide dismutase. Results were analyzed by t-test (unpaired) and $\mathrm{p}<0.05$ was considered significant. 


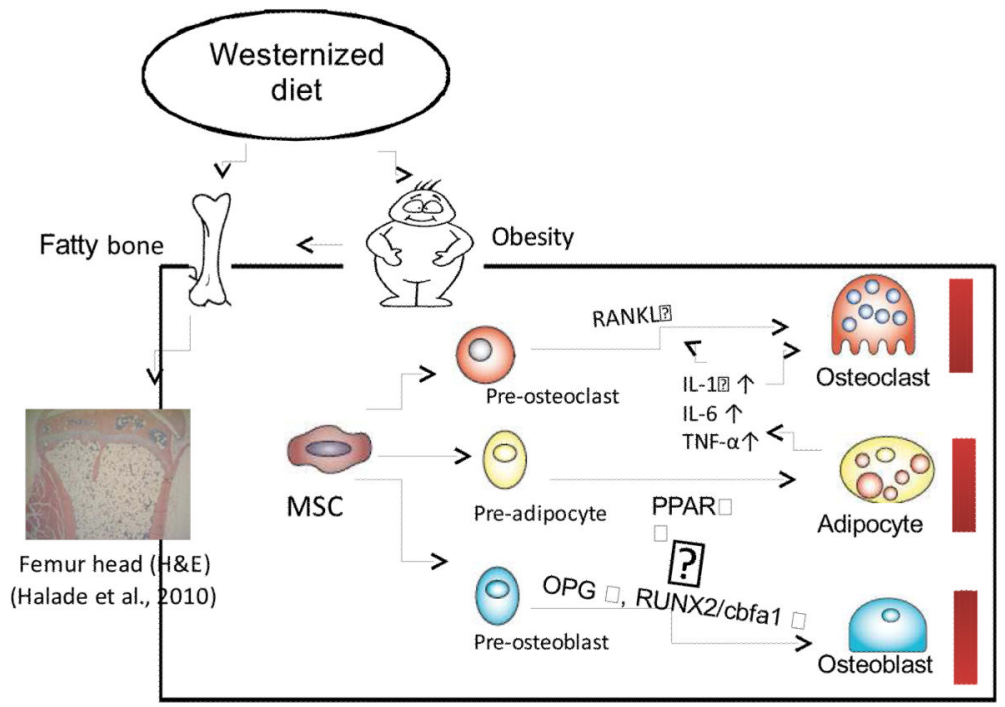

Figure 9.

Two primary mechanisms promote increased osteoclastogenesis and bone resorption in obesity. Increased BM adiposity (Halade et al., 2010) produces elevated levels of proinflammatory cytokines IL-1 $\beta$, IL- 6 and TNF- $\alpha$. These cytokines promote increased RANKL expression in stromal cells, which leads to enhanced osteoclastogenesis. Furthermore, increased PPAR $\gamma$ leads to adipogenesis, resulting in lowered RUNX2/cbfa1 and OPG expression and eventually to reduced bone mass. 